\title{
Earth observation for the assessment of environmental and societal impacts of mining activities and after mine closure - the EO-MINERS project
}

\author{
H. Hejny Mineral Industry Research Organisation, UK
}

\begin{abstract}
Given the current status of political discussion in Europe about raw materials problems, the sustainable development of the extractive industry and the reduction of its environmental footprint are among the key topics in this discussion. In this context, the European Commission approved the EO-MINERS project (Earth Observation for Monitoring and Observing Environmental and Societal Impacts of Mineral Resources Exploration and Exploitation).

One of the scientific and technical objectives of EO-MINERS is to assess policy requirements at macro (public) and micro (mining companies) levels and define environmental, socio-economic, societal and sustainable development criteria and indicators to be possibly dealt using earth observation (EO) technologies. Further to that, the project will use existing EO knowledge and carry out new developments on three demonstration sites (Sokolov lignite mining area, Czech Republic, Witbank coal field, South Africa, Makmal gold mine, Kyrgyzstan) to further demonstrate the capabilities of integrated EO-based methods and tools in monitoring, managing and contributing towards reducing the environmental and societal footprints of the extractive industry during all phases of a mining project, from the exploration to the exploitation and closure stages. Finally, it will provide reliable and objective information about affected ecosystems, populations and societies, to serve as a basis for a sound 'trialogue' between industrialists, governmental organisations and stakeholders.
\end{abstract}

The paper will discuss only results obtained so far, as the project is scheduled to run until October 2013. The project will further indicate ways in which the project results and products may be used for monitoring purposes beyond the operational phase of a mine.

\section{Introduction}

The extractive industry has played a fundamental role in the development of a modern society in many countries all over the world. The industry has been, and continues to be, an important contributor to both national and regional economies and is critical to national defence.

The world today is facing an increasing mineral resource demand. This has been illustrated by the European Commission Vice President Günter Verheugen, responsible for enterprise and industry policy, who said: "European industries need predictability in the flow of raw materials and stable prices to remain competitive. We are committed to improve the conditions of access to raw materials, be it within Europe or by creating a level playing field in accessing such materials from abroad".

In recent years, the EU's total material requirement has remained at a constantly high level - roughly $50 \mathrm{ta}$ year per head of the population since the middle of the 1980s. But in this time the weight of imports and their environmental impacts have considerably increased (EEA, 2003). The bulk of this increase is attributable to ores, fossil fuels, metalware and products such as glass, ceramics and precious stones. These four categories are responsible for most of the ecological impact of imports. More than half of these materials originate from developing countries, while fewer resources are extracted from within Europe itself. Numerous mines have closed in Europe during the last few decades, either because of natural exhaustion or because they were no longer profitable. With the closure of mines environmental pressure 
has been reduced in Europe but has risen in other regions. The environmental footprint of EU material consumption has shifted from Europe to other regions.

At the same time, the ecological impacts of imports into the EU have increased. One tonne of imports leaves behind an average amount of five tonnes in mining waste, emissions and erosion in the exporting country (Schütz et al., 2003). This ratio has more than doubled over the past 25 years, and in the case of ores has quadrupled from 1:4 to 1:16. This suggests that the acquisition of raw materials is becoming more and more costly, that more energy has to be used, and that more waste is left behind by mining operations.

The global dimension of this problem is being increasingly recognised. Access to raw materials was on the agenda of the G8 Summit on 6-8 June 2007. On that occasion a Declaration on "Responsibility for raw materials: transparency and sustainable growth" was adopted, which addresses the key priorities for a sustainable and transparent approach to this question. In addition, the Competitiveness Council meeting on 21 May 2007 has invited the Commission to develop a coherent political approach to the issues arising. As a result, the European Commission launched in autumn 2008 'The Raw Materials Initiative - Meeting Our Critical Needs for Growth and Jobs in Europe' (European Commission, 2008).

The exploitation of natural resources in many developing countries has been considered as a vital part of economic growth, employment and infrastructure development, but it has come at a cost to the environment. Early mining operations have left a historical legacy of negative environmental impacts that affect our perception of mining. With the emergence of the concept of sustainable development, it is now recognised that environmental protection is as fundamental to a healthy economy and society as it is to development. The challenge is to simultaneously promote both economic growth and environmental protection.

The responsible management of Earth's environment is one of today's most pressing concerns and a central motivation for the Group on Earth Observations (GEO). Sound environmental management of mining activities can avoid high remediation costs, which frequently drain public funds. Surface and groundwater pollution, soil contamination, and terrain instability all cause damage that can affect society. Understanding and monitoring pollution processes in mining areas is therefore of concern to a very wide user community, including central government bodies or agencies, local authorities, industry, environmental groups and individual citizens. Faced with legal and social pressures, the mining industry is also interested in minimising the impacts on environment and society. Formerly due to often accumulating remediation costs, nowadays these activities play an important role at the stock market and an increasing environmental awareness is an essential aspect of modern mining management. But the technology platform to support such critical environmental monitoring is diverse, geographically inconsistent, site specific, lacks integration across technologies and is therefore far from complete. Understandably, it is currently a gap within GEO's Global Earth Observing System of Systems, which concentrates on issues such as Disasters and Climate Change.

The non-energy extractive industry (NEEI) of the EU-25 generated a direct turnover of about $€ 40$ billion (about US\$ 48 billion), and provided employment to about 250,000 people in 16,629 enterprises in 2004 (European Commission Staff Working Paper, 2007). Estimated indirect employment provided by NEEI industry is up to 4 times greater than those directly employed, and is clearly a significant contributor to the economy of the EU. The use of these primary raw materials in the products of other branches of EU industry means they have a central role in guaranteeing industrial and economic sustainability. Nevertheless current demand exceeds production, and so the EU is heavily dependent on mineral and metal imports leading to an annual trade deficit of about $€ 11$ billion (about US\$ 15 billion, European Commission Staff Working Paper, 2007). Metallic minerals accounted for $90 \%$ of this deficit (€10 billion, about US\$13.7 billion), while there were also net trade deficits in construction minerals (€456 million, about US\$ 625 million) and industrial minerals ( $€ 798$ million, about US\$ 1.1 billion).

Several national and international initiatives, both from the private or the institutional sectors, have been developed to address the sustainable development of the extractive industry and the reduction of the environmental footprint. 
One can cite:

- Both the EU's 2001 Sustainable Development Strategy (SDS) (renewed in 2005 (European Commission, 2005b)) and the 2005 Thematic Strategy for the Sustainable Use of Natural Resources (European Commission, 2005a) aim at a decoupling of economic activity from environmental impacts by considering the entire life cycle of resource use. This means that environmental impacts are considered at each stage of the life-cycle of the product and the raw materials - during extraction, transport, processing/refining, the use phase of the products made from it, and when a product or raw material becomes waste at the end of its useful life - thus avoiding negative impacts being shifted to other environmental media, to other stages of the lifecycle, or to other countries.

- The ETP-SMR Strategic Research Agenda (SRA) (ETP-SMR, 2009). The related Implementation Plan (IP) focuses on ways and means to implement the most urgent activities outlined in the SRA. In particular the Short Term Research Priority 8 mentions "Helping cities in mining regions secure their strategic land, water and biodiversity resources by the use of modelling and economic tools" (ETP-SMR, 2007)

- The International Council on Mining and Metals (ICMM) has committed members to its Sustainable Development Framework (ICMM, 2003). This framework comprises three elements and a set of 10 Principles (including a set of supporting position statements), public reporting and independent assurance. The framework has been developed systematically since the formation of ICMM in 2001, with its foundations in the Mining, Minerals, and Sustainable Development (MMSD) project.

- The Sustainable Development indicators in the Mineral Industry (SDIMI) is an international forum whose objective is to assist mining and minerals industries in their global transition to sustainable development. SDIMI states that;

"Meeting the development needs of the world's growing population without depriving future generations of the means to meet their own needs, better known as Sustainable Development is the key challenge facing the minerals and mining industry. At present, a special focus of public perception is placed on environmental and social consequences of mining. Growing environmental and social concerns, supply chain procurement standards as well as public pressure and regulatory measures will profoundly shape the global mining business in the near future. In order to cope with these challenges the mining and minerals companies are forced to integrate sustainable development as well as stakeholders' participation into their business strategies and policies. Up to now there are on-going discussions and projects on the development of sustainability indicators however these different efforts haven't resulted into a common agreement yet" (SDIMI, 2010).

- African Mining Vision 2050 (African Union, 2009) is a Task Force developed under the auspices of the United Nations Economic Commission for Africa (ECA). The taskforce, jointly established by the African Union (AU) and ECA, also includes representatives from the African Mining Partnership (the intergovernmental forum of African ministers responsible for mining), the African Development Bank (AfDB), UNCTAD, and UNIDO. Among short term (less than five years) objectives are: a) Improve public participation (Consultation and information sharing/participatory decision making/dispute resolution mechanism) in the mining sector, and b) capacity building.

- Sixteen African ministers responsible for mining in their respective countries have launched the African Mining Partnership (AMP), with the aim of championing and coordinating mining and mineral-related initiatives under the auspices of NEPAD - the New Partnership for Africa's Development. The ministers have identified mining programmes and projects in six key areas: Artisanal or small-scale mining; harmonisation of mining policies; environment and sustainable 
development; beneficiation; human resource development; and promoting foreign investment and indigenous participation in mining ventures.

\section{Project objectives}

\subsection{General objectives}

The aim of EO-MINERS is to bring into play EO-based methods and tools to facilitate and improve interaction between the mineral extractive industry and the society in view of its sustainable development while improving its societal acceptability.

\subsection{Strategic objectives}

Mining companies, regulatory bodies and stakeholders need various EO-based tools and methods adequately juxtaposed regarding the local contexts and applications (in compliance with GEO and GMES (Global Monitoring for Environment and Security) objectives and tasks).

Forecasting impacts, footprints, and relevant remediation measures require developing prospective tools. GIS (Geographic Information System) using EO data will enable to visualise prospective evolution over time (flow modelling), playing on one or several GIS-layer parameter. For instance, population migration is often taken into account during the feasibility phase, but not properly monitored further.

Cumulative impacts must be adequately addressed at regional scale (valley, district, county, etc.), including induced impacts (population migration, livestock impact, etc.) with respect to the concept of heavily exploited area.

As the EU is strongly interested in the establishment of measures for raw material flow analysis, especially for imported mineral resources, this project will contribute to the development of measures that can be used to analyse the mining operations taking the individual potential ecological and social footprint into account. Thus, the project directly supports the monitoring of three major EU policies:

- The Sustainable Development Strategy.

- The Raw Materials Initiative.

- The Thematic Strategy for the Sustainable Use of Natural Resources.

Eventually these developed methods and products should be integrated into Environmental Management systems (ISO 14001) and such integration must be properly addressed.

\subsection{Scientific and technical objectives}

The scientific and technical objectives of EO-MINERS are three-fold:

- Assess policy requirements at macro (public) and micro (mining companies) levels and define suitable criteria and indicators for using EO:

- Environmental criteria and indicators.

- Socio-economic criteria and indicators.

- Societal criteria and indicators.

- Sustainable development criteria and indicators.

- Use existing EO knowledge and carry out new developments on demonstration sites to:

- Further demonstrate the capabilities of integrated EO-based methods and tools in monitoring, managing and contributing towards the reduction of the environmental and societal footprints of the extractive industry during all phases of a mining project, from the exploration to the exploitation and closure stages. 
- Contribute making available reliable and objective information about affected ecosystems, populations and societies, to serve as a basis for a sound 'trialogue' between industrialists, governmental organisations and stakeholders, where a trialogue is defined as, "an interchange and discussion of ideas among three groups having different origins, philosophies, principles, etc." (Webster's New World College Dictionary, 1999).

- Establish a baseline for a compendium of best practise approaches that will assist the ongoing and necessary dialogue between society and mining industry by summarising and documenting the developed models and algorithm, as well as the results of the 'trialogue'.

- Capacity building, communication and dissemination among:
○ ETP-SMR.
- International and national organisations (EU, AU, UNEP, UNECA, etc.).
- Extractive industry associations and individual companies.
○ Governmental representations.
○ NGOs.

\section{Methodology}

The work plan (Figure 1) starts with the identification of the needs from industry, regulatory bodies and other stakeholders (e.g. society and NGOs) to evaluate the indicators and parameters to be taken into account in the assessment of the environmental, socio-economic and societal footprints of the extractive industry at each life-cycle stage of a project. Corporate level (extractive industry and relevant associations) as well as public level (regional, national to international) will be considered.

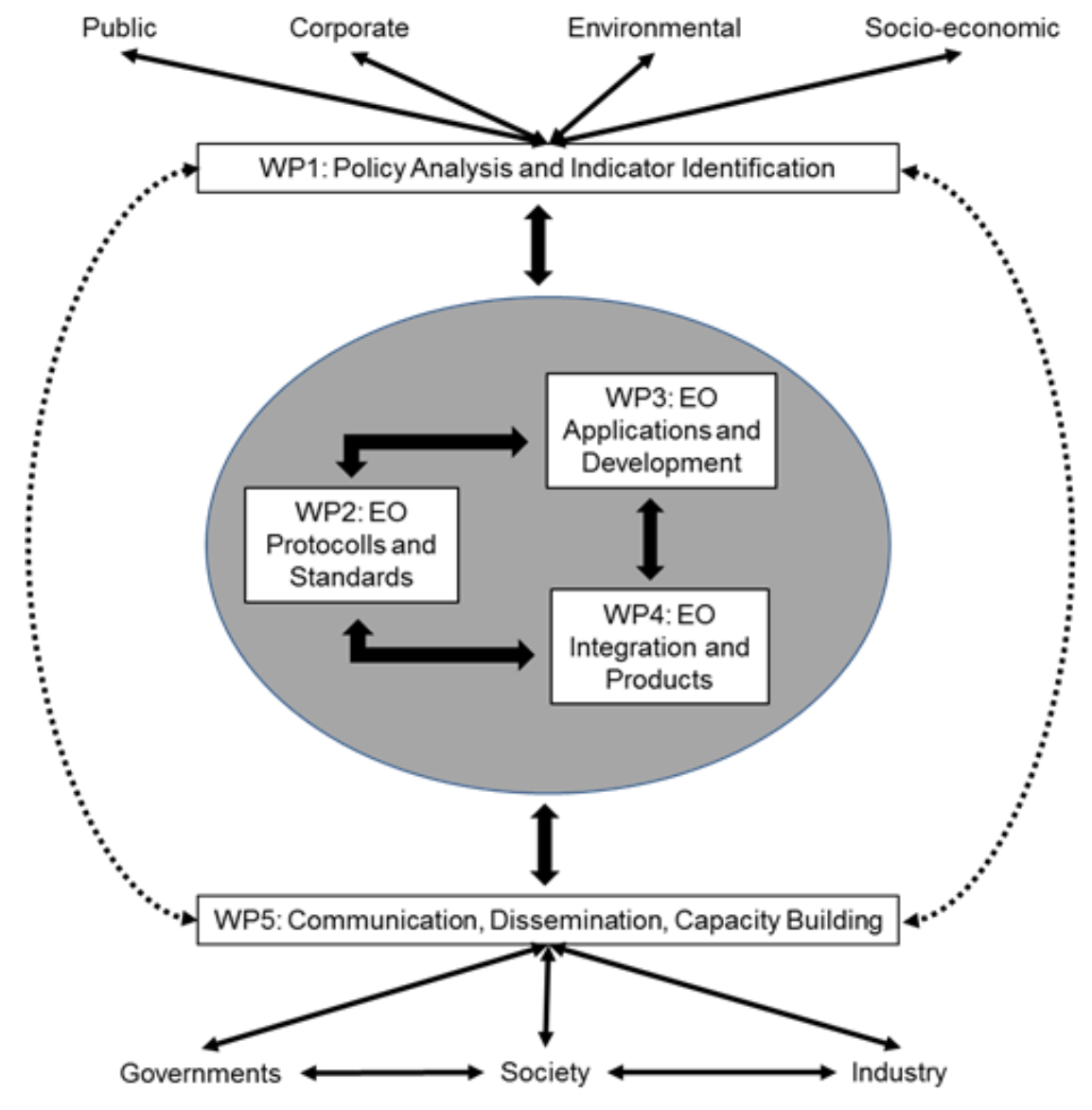

Figure 1 The EO-MINERS work plan 
This stage will serve as the basis for:

- Identifying parameters and indicators that can be addressed by EO methods, and to be used during the EO tools and methods development phase over demonstration sites.

- Identifying stakeholders to be addressed during the dissemination phase at the end of the project.

A strong research and development component will be applied in developing EO-based tools and methodologies to observe and monitor the environmental and societal footprint of extractive industry activities over three demonstration sites located in heavily exploited areas:

- In Europe: Sokolov lignite open cast mine in Czech Republic.

- In Southern Africa: Witbank Coalfields, Mpumalanga Province, South Africa.

- In Central Asia: Makmal gold mine in Kyrgyzstan.

Innovation will be achieved by the juxtaposition and/or fusion of various EO data through models or data integration schemes which fit at best with: i) site specific requirements, and ii) the parameters and indicators to be addressed as defined during the previous stage.

Particular attention is paid to the definition and application of protocols and standards for EO data and added value products that guarantee their 'quality and objectivity'. Those tools are not questionable even in discussions between different parties involved in a mining project life. This contributes to improved social acceptability of the extractive industry.

Dissemination activities are addressed through:

- Communication, dissemination and capacity building: The target audience will include, but not be limited to, the European Technology Platform on Sustainable Mineral Resources (ETP-SMR, 2009), national and international organisations (e.g. EU, UNEP, UNECA, etc.), the extractive industry and their trade associations, and NGOs.

- Initiating and developing a sound 'trialogue' between the three main groups involved, the industry, governmental organisations and other stakeholders (e.g. NGOs) based on reliable and objective information about ecosystems, populations and societies affected by mining activities.

\section{$4 \quad$ Work done so far}

The EO-MINERS project is scheduled to run until October 2013. Therefore, the project hasn't yet produced many results.

The work has concentrated on the following topics:

- Policy assessment.

- Development of indicators.

- On-site and airborne data collection and assessment.

- Dissemination activities.

\subsection{Policy assessment}

For the selection of applicable EO techniques, the project has identified and analysed policies related to the footprint of mining industries, at corporate, authority and civil society level. Information requirements have been derived and appropriate indicators assessed and selected for all three levels, covering both social and environmental indicators of corporate sustainability reporting and macro-economic indicators for governmental policy-making. The results of the analyses will define the demand for the development and application of EO services by the ETP-SMR and thus frame subsequent work. In a final iteration loop, the response to the tested EO services will be analysed. 
Concerning sustainable mineral resource use, a variety of stakeholders at different governance levels (from local to global level) could be identified. Their policies (or strategies and agendas) have different objectives that potentially can be supported by EO services. Hence, in a first step such policies and strategies related to mining activities at three different levels were reviewed in order to identify core concerns.

This policy analysis provided the basis for identification of general information needs and derivation of macro indicators related to minerals extraction. This macro policy analysis complements the analysis at micro level at three test sites, including conceptual site models, expert deliberations and local stakeholder consultation to indicate the information needs with supporting site-specific indicators. On the basis of this macro policy analysis stakeholders, which play a role in selected policies, will be consulted in the course of the planned European trialogue activities.

The analysis of policies has shown that there is no clear demand for macro indicators from corporate and non-governmental stakeholders. Even though industry and civil society organisations participate in activities like the Extractive Industries Transparency Initiative (EITI), the UN Global Compact Initiative or the Intergovernmental Forum on Mining, Minerals, Metals and Sustainable Development, the EU Raw Materials Initiative, national or intra-governmental organisations are still the main driver of macro level regulations on sustainable mining practice. Thus, governmental organisations create the main demand for macro indicators and potentially for EO data.

There are a broad range of different public policies and initiatives on sustainable development, resource policies, environmental protection and mining. Some of these are general and based on voluntary agreements, while others constitute a binding regulatory environment for mining operations. The policies and initiatives have different scopes and scales. Although this has not lead to a comprehensive international framework regulating extractive activities, the international discourse tends towards more stringent legislation.

Public policy initiatives create a demand for information on sustainable mining activities at the macro level. They can be clustered into four main categories:

1. Sustainable development policies.

2. Resource policies.

3. General environmental policies.

4. Specific environmental policies.

International policies and initiatives address mainly resource-supplying countries, often with emphasis on good governance and income distribution. For the use of physical indicators, which could be provided by $\mathrm{EO}$, the EU has established a tight and comprehensive regulatory and policy framework on mining activities. This comprises general resource policies such as the Thematic Strategy on the Sustainable Use of Natural Resources and the Raw Materials Initiative, as well as a wide range of specific environmental regulations in the fields of biodiversity, air, water, waste, etc., most notably the Mining Waste Directive.

The general and specific environmental policies of the EU might be best addressed with site-specific indicators. The resource policies of the EU, however, generate a specific demand for information about mineral resources by national and EU statistical services. This would require the development of specific EO-services on the macro level.

With the Flagship Initiative for a Resource-efficient Europe and the Innovation Partnership for Raw Materials EU resource policies have gained momentum. An emerging directive on EU environmental satellite accounts complements their information demand. The minerals-related indicator development for both, EU resource policies as well as EU environmental satellite accounts rely heavily on Economy-wide Material Flow Accounts (EW-MFA). This might offer considerable opportunities for EO-MINERS and other earth observation activities related to mining such as the GEOSS social benefit area on Energy and GeoResource Management. 


\subsection{Development of indicators}

The project will develop material that will be used in deriving and defining indicators for various issues that EO-MINERS will. The process of defining indicators is designed in a way that not only the various technical communities within EO-MINERS will contribute to a valid and useful set of indicators, but also a wide variety of stakeholders outside the project team.

During the research on corporate policies, public policies and civil society it became evident that there are two main categories of policies with very different information requirements:

- Site-specific policies of local and regional public authorities, companies and NGOs, which requires information about specific local and regional impacts of the mining site which can be addressed with site-specific micro-indicators.

- National and international policies of multinational companies, mining associations, governmental bodies and civil society that require general information about mines and the mining sector, which need to be addressed by unspecific macro-indicators.

\subsubsection{Site-specific indicators}

There are site-specific policies of public authorities, mining companies and civil society which require specific information about the local situation and problems.

These specific problems can be subject to local debate about the sustainability of mining activities among the different governmental and non-governmental stakeholders. These problems have been discussed with various stakeholders at the EO-MINERS test sites.

The development of micro indicators with the potential of being relevant for the different test sites went through several iterations of enlargement and refinement (Falck et al., 2011). These indicators were developed on the basis of perceived stakeholders' needs rather than on what could be observed using EOtechniques. From the fieldwork it also became clear that the majority of stakeholders are not very well informed about the capabilities of EO-techniques.

Therefore, the stakeholder elucidation (interview and subsequent assessment) on site-specific indicators, which were formulated independent of the EO technology development, were complemented with expert elucidation from the EO-MINERS consortium. After the field trips to the test sites, the EO-MINERS experts have the advantage of a (limited) knowledge of the site-specific problems based on their interviews with the stakeholders, direct visual observation of the site as well as background research.

The third source for developing the site-specific indicators is the conceptual model for each site.

The multi-pronged approach to developing indicators (Figure 2) consisted of a heuristic development by expert elucidation, site-specific conceptual models for the three study sites and a deliberative approach elucidating outside stakeholder input. These three processes were run in parallel and once the three sets of indicators had been derived they were analysed for their respective coverage. For instance, conceptual site models were analysed for any processes or features that had not been covered by the set of 'expertderived' indicators and the latter were updated accordingly. This process went through several iterations to consolidate the various sets of indicators into one set. This consolidated set of indicators, together with results from EO services based on them, will be subject to final stakeholder evaluation towards the end of the project.

The project is currently in the process of linking the derived indicators with EO techniques. One important lesson learnt from the interviews conducted at the test sites in the Czech Republic and in South Africa as well as from presenting the list of candidate indicators to the interviewees was that not many understood the possibilities EO-techniques have to offer.

An extensive matrix was therefore compiled for each of the three demonstration sites, which tabulate the stakeholder-driven indicators with the environmental parameters in the Conceptual Site Models along with 
the EO data available to the EO-MINERS project. The matrix is a very important step because it is being used within the project as a decision-making tool to determine the range of EO products that could potentially be made in response to the stakeholder requirements. EO-MINERS does not have the resources to make all of the possible EO products so this matrix will also help us to prioritise which products we will make.

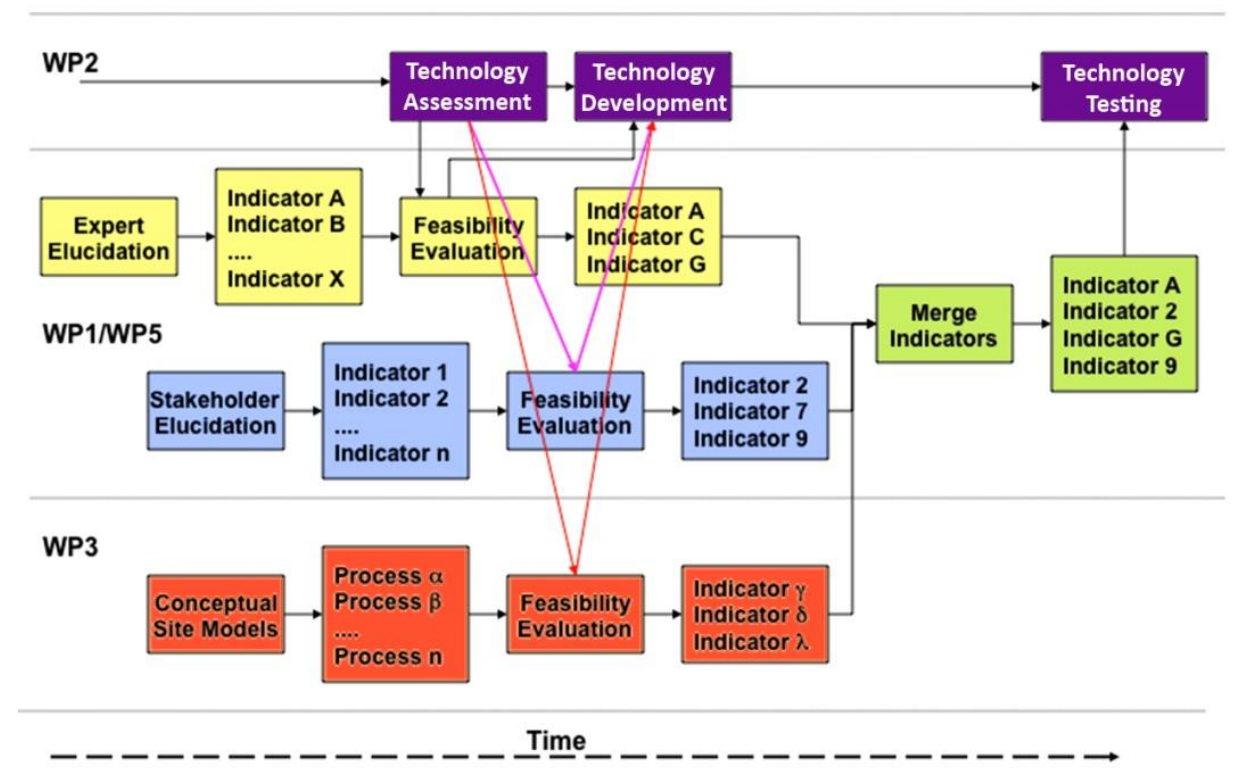

Figure 2 Multi-pronged approach to develop site-specific indicators

\subsubsection{Consolidated set of indicators}

The development of a set of indicators based upon previous knowledge about mining-related issues. These indicators reflect known environmental and societal issues at mining sites as well as the interest (as perceived by the experts represented in the EO-MINERS project team) of various relevant stakeholder groups. Table 1 shows the candidate indicator categories.

\subsubsection{Macro indicators}

The macro indicators relevant for EO-MINERS contain aggregated, general (site-unspecific) information about the impact of mining activities. This information meets the needs of national or international stakeholders for their decision-making. Their policies and information needs are generated on higher political levels than the local level of a specific site. For the identification of information requirements on a macro level the conceptual site models and local stakeholder consultations are therefore of lesser importance.

The conceptual site models are part of the 'site-specific available data collection'. Available data at the sites can be relevant to inform macro policies, but they are not necessarily identifiable as such (e.g. local information about a protected site, which falls under the Natura 2000 directive). The interviews with local stakeholders can reveal some link to macro-policies, but so far this link has not played a major role. Also the expert elucidation focused primarily on site-specific problems and rarely had a connection to the information requirements on a macro-level.

As the conceptual site models, expert deliberations, and local stakeholder consultation cannot fully satisfy the information needs for national or international policies, a policy analysis on EU and international levels has been chosen as an appropriate methodology to identify general information needs. In order to verify the results of the policy analysis the identified stakeholders, which play a role in selected policies, will be consulted in the course of the European trialogue activities. 


\section{Table 1 Candidate indicator categories}

\begin{tabular}{ll}
\hline & \multicolumn{1}{c}{ Indicator Category } \\
\hline A & Land use \\
B & Mass flows \\
C & Energy flows \\
D & Air quality and other nuisances \\
E & Water quality \\
F & Transport \\
G & Geotechnical hazards and accidents \\
H & Industrial and other accidents \\
I & Social impacts \\
J & Regional development \\
K & Economic vulnerability/resilience \\
\hline
\end{tabular}

As one example, Table 2 shows the consolidated set of indicators for category A - land use.

\section{Table 2 Example: Consolidated set of indicators, category A - land use}

\begin{tabular}{ll}
\hline & \multicolumn{1}{c}{ A - Land Use } \\
\hline A1 & Total land use by mining and milling - topographical footprint \\
A2 & Mining land use intensity - topographical footprint versus amount of marketable product \\
A3 & Artisanal and Small-Scale Mining - topographical footprint of ASM sites \\
A4 & Residential land use - residential developments around mining areas \\
A5 & Informal settlements - sprawl of squatters areas, slums \\
A6 & Sites set aside, protected areas - nature reserves, wetlands, sites of spiritual value and similar \\
A7 & Recultivation success on mined-out areas and waste/spoil heaps \\
A8 & Areas indirectly affected and its potential use - Impact of mining on the potential use of \\
& operation and surrounding areas, impact on land value/prices (opportunity cost) \\
A9 Soil fertility of remediated mine areas & E10
\end{tabular}

\subsection{On-site and airborne data collection and assessment}

EO-MINERS through its partners has access to a number of different data sets and measuring techniques. They all can and will be used to serve the overall objective of the project to provide reliable and objective information about affected ecosystems, populations and societies as basis for a sound 'trialogue' between industrialists, regulatory bodies and stakeholders towards the end of the project. Table 3 shows a compilation of the different methods.

The project is currently in the phase of pre-processing data. Preliminary mineral mapping has started and work on quality indicators for the airborne hyperspectral survey data in the thermal infrared wavelength domain is continuing. The production of vegetation health and mineral maps over the Czech site has started using the 2009 and 2010 hyperspectral airborne data set. Development in change detection 
algorithms led to the mapping of changes related to mining exploitation over the Czech site between these dates. A thermal infrared airborne survey has been performed over the South African site using a single band thermal infrared sensor system (FLIR). The data are currently being processed. The installation of the ALERT system in South Africa has been completed and the system is ready for acquiring data. Processing of DEMs (digital elevation model) for drainage pattern computation has started over the Czech and Kyrgyz sites with the objective of evaluating possible surface contamination pathways.

\section{Table 3 Earth Observation tools and methods}

\begin{tabular}{ll}
\hline Data Source & Tools And Methods \\
\hline Satellite data & Conventional optical sensors: Landsat Thematic Mapper, ASTER \\
& Very high resolution optical sensors, such as Ikonos, Quickbird, WorldView II, \\
SPOT 5 & Radar sensors, in particular for INSAR applications \\
Airborne data & Airborne imaging spectroscopy (hyperspectral) survey \\
& Airborne geophysics: radiometric, electromagnetic, aeromagnetic \\
& Thermal infrared (multi and broad band) \\
Time-lapse electrical resistivity tomography (ALERT) \\
Ground monitoring networks \\
methods
\end{tabular}

Adar et al. (2011) and Chevrel et al. (2011) have already presented preliminary results. The reader is referred to these references for more details.

The following figures illustrate some examples of results obtained from data analysis. Figure 3 refers to the Czech site. It demonstrates the use of airborne imaging spectroscopy (HyMap) for mineral and vegetation mapping.
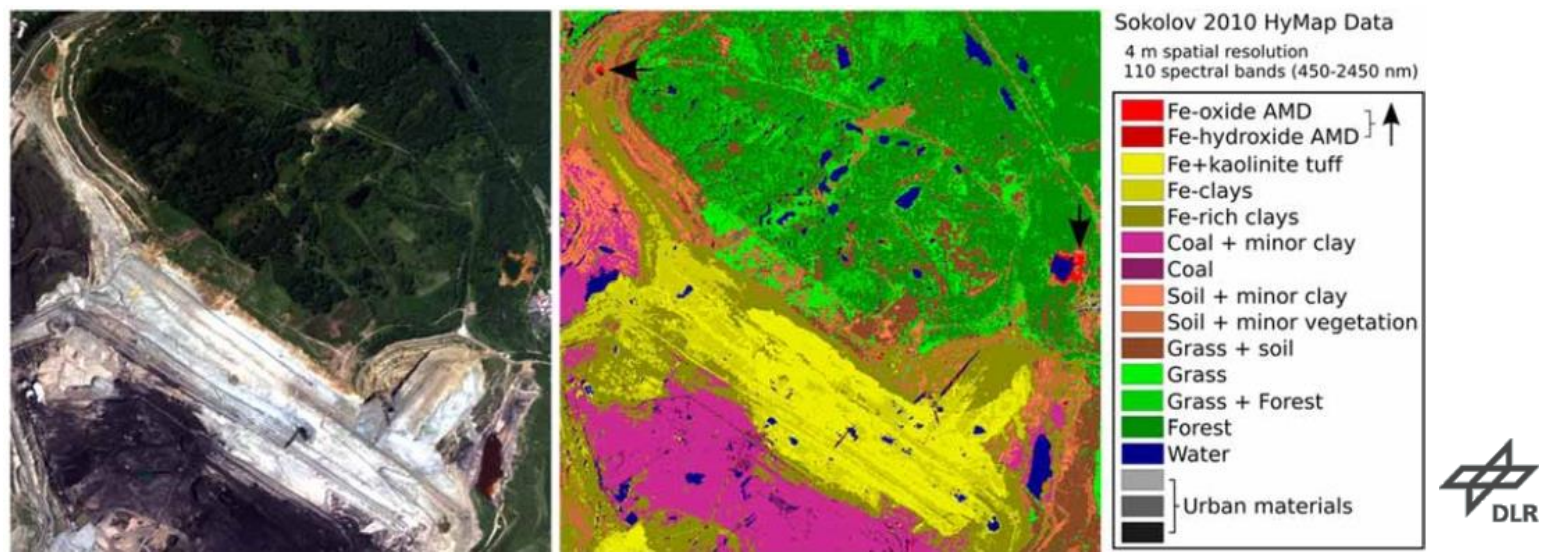

\section{Figure 3 Exploitation of airborne imaging spectroscopy (HyMap) for mineral and vegetation mapping (pers. comm., EO-MINERS partners, 2012)}

Figure 4 shows vegetation health mapping also from the Czech site. It shows the status of trees that have not shown any visual damage symptoms. 

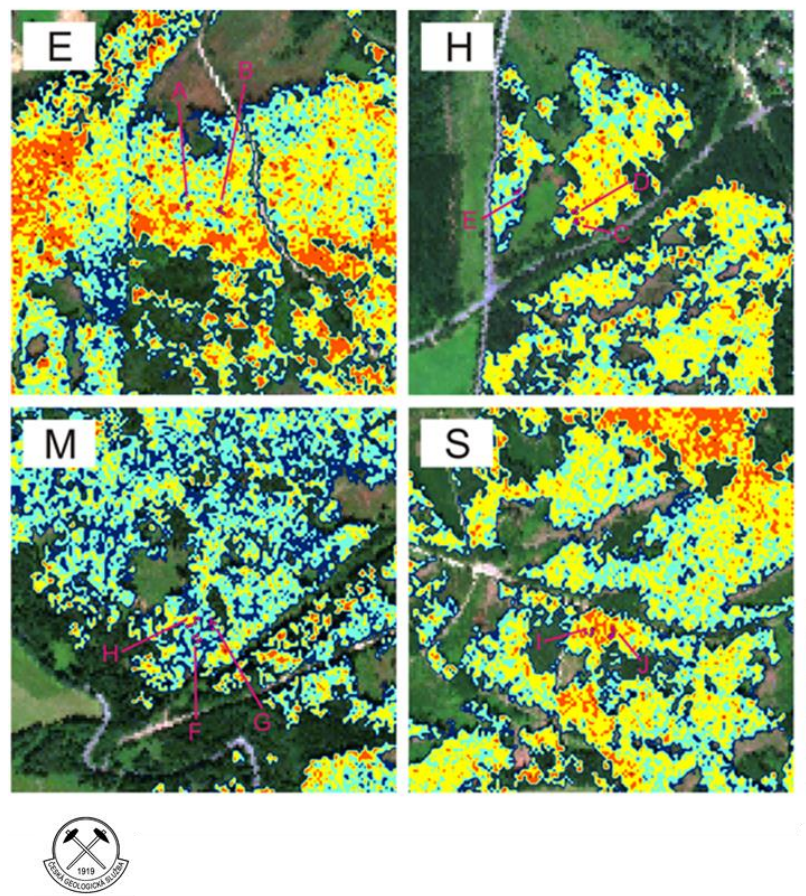

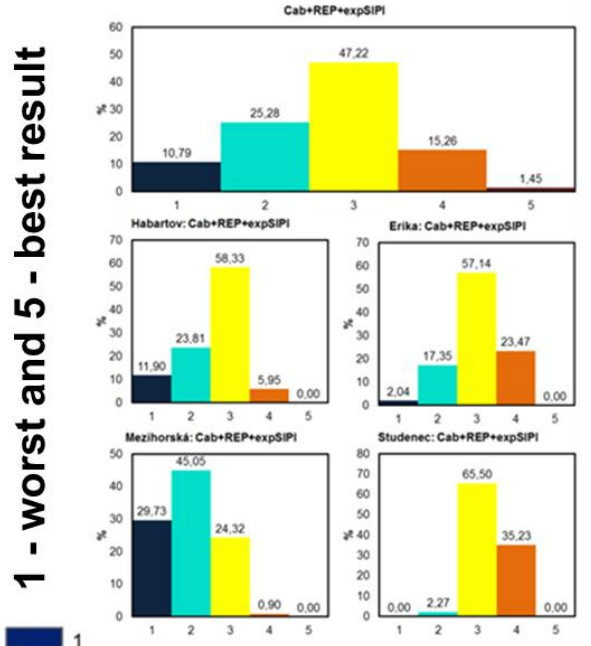

Relative frequencies (\%): The entire Sokolov lignite basin area (top) and the individual sites Erika (E), Habartov (H), Mezihorská (M) and Studenec (S)

Figure 4 Vegetation health mapping from the Czech site (pers. comm., EO-MINERS partners, 2012)

Figure 5 shows change detection from HyMap imagery. The figure shows the results of a new innovative method developed in the project together with error estimation procedure.

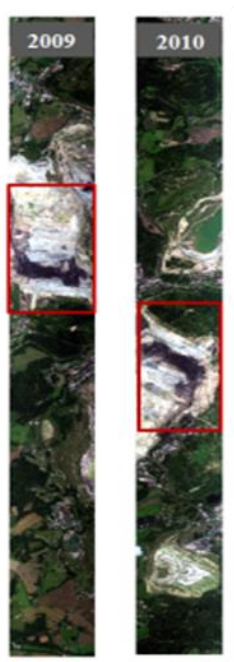

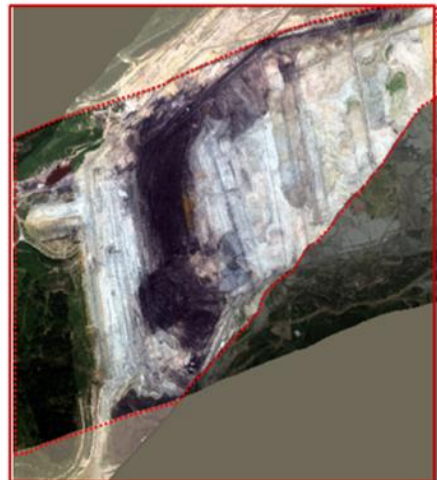

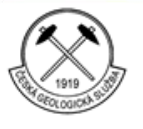

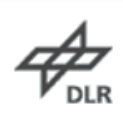

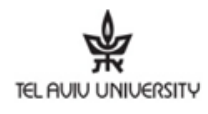

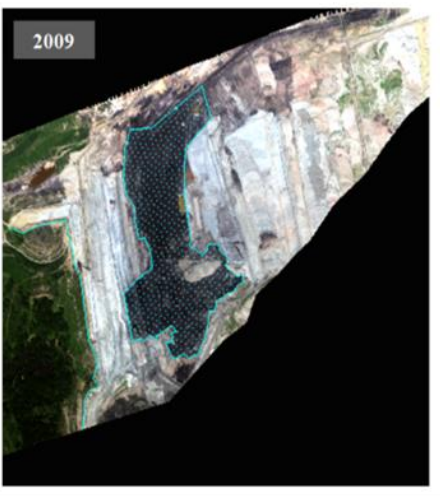

Coal mine area progress in one year

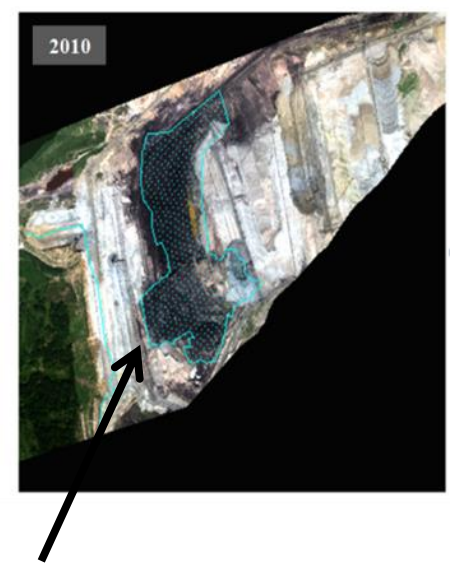

\section{Figure 5 Spectral based change detection, innovative methods and error estimation} (pers. comm., EO-MINERS partners, 2012)

\subsection{Use of results in post mining applications}

The project aims primarily at developing EO-based tools for monitoring and observing the impact on the environment and on the society of mining activities. The project results and products will be verified at the chosen example test cases, which are all in the operational phase. However, post-closure objectives require consideration in almost every stage of a mining project. Therefore, the monitoring products developed in the frame of EO-MINERS are equally beneficial in post mining applications. 
Once verified, the products need to be adapted to the specific conditions for each application, e.g. the data fusion and specific processing algorithms will take into account site conditions and various thematic requirements defined by the operator of the post mining site and probably other stakeholders involved in monitoring. The GIS thematic map layers produced from the data available will then be used for footprint assessment and risk analysis.

The process described in the EO-MINERS project - policy assessment -> indicator identification -> choice of suitable EO tools able to serve monitoring task $\rightarrow$ social dialogue among stakeholders involved based on objective information - will also apply to post mining monitoring. The key to success will be the right choice of indicators addressing the problem and subsequently the right choice of suitable EO tools and finally the willingness of all stakeholders to find a common solution.

\section{Conclusions}

Mining and the extractive industry will continue to play a significant role in the socio-economic development of many countries all over the world. The social acceptability of a mining project, from exploration to closure and beyond, is among the major key issues to be dealt with.

EO-MINERS has already completed the first steps of policy assessments and indicator development. The project is now working on developing innovative approaches in EO data sets processing and mapping as well as on linking the indicators to EO techniques in order to provide the most suitable EO methods and tools for the envisaged tasks.

The first steps of the EO-MINERS project have been successful, increasing confidence in achieving the project objectives. Irrespective of where the EO data sets originate, or whether the site to be monitored is still in operation or already closed, EO-MINERS will in principle provide suitable monitoring tools.

\section{Acknowledgement}

The author wishes to acknowledge the various contributions from the EO-MINERS project team (http://www.eo-miners.eu/).

The EO-MINERS project is running with financial support from the European Commission under the Seventh Framework Programme, FP7-ENV-2009-1, Grant Agreement No 244242.

\section{References}

Adar, S., Notesco, G., Brook, A., Livne, I., Rojik, P., Kopacková , V., Zelenkova, K., Misurec, J., Bourguignon, A., Chevrel, S., Ehrler, C., Fisher, C., Hanus, J., Shkolnisky, Y. and Ben Dor, E. (2011) Change Detection over Sokolov Open-Pit Mining Area, Czech Republic, Using Multi-Temporal HyMAP Data (2009-2010), in Presentation and paper at the SPIE RS 2011, L. Bruzzone (ed.) 19-22 September 2011, Prague, Czech Republic.

African Union (2009) African Mining Vision 2050.

Chevrel, S., Ben Dor, E., Fischer, C., Kopackova, V., Jordan, C., van Tonder, D., Adar, S. and Ehrler, C. (2011) Monitoring the Environmental and Societal Impacts of Mining - The EO-MINERS project, in Presentation at the GRSG Annual meeting, Frascati, Italy, 7-9 December 2011.

European Commission (2005a) COM (2005)670, Thematic Strategy on the sustainable use of natural resources.

European Commission (2005b) COM (2005)658 final, On the review of the Sustainable Development Strategy - A platform for action.

European Commission (2008) COM (2008)699, The Raw Materials Initiative - Meeting our Critical Needs for Growth and Jobs in Europe.

European Commission Staff Working Paper (2007) SEC (2007)771, Analysis of the competitiveness of the non-energy extractive industry in the EU.

EEA (2003) European Environment Agency. Europe's environment, the third assessment.

ETP-SMR (2009) European Technology Platform on Sustainable Mineral Resources. Strategic Research Agenda, Rev 3.

ETP-SMR (2007) European Technology Platform on Sustainable Mineral resources. Implementation Plan.

Falck, E., Blanchard, F., Solar, S.V., Spangenberg, J.H. and Wittmer, D. (2011) Stakeholder-Driven Enablement Through EarthObservation Information - The project EO-MINERS, in Presentation at the SRMINING 2011, First International Seminar on Social Responsibility in Mining, Santiago, Chile, 19-21 October 2011.

ICMM (2003) International Council on Mining and Metals. Sustainable Development Framework - 10 Principles. 
Schütz, H., Moll, S. and Bringezu, S. (2003) Globalisierung und die Verlagerung von Umweltbelastungen, Wuppertal Papers, Wuppertal Institut für Klima, Umwelt, Energie GmbH.

SDIMI (16/08/2010) SDIMI.org. An International Forum for Sustainable Development Indicators in the Minerals Industry Objectives, viewed November 2008, http://www.sdimi.org/sdimi_obj.htm

Webster's New World College Dictionary, 4th Edition (August 1999) John Wiley \& Sons Inc. 